University of Montana

ScholarWorks at University of Montana

Graduate Student Theses, Dissertations, \&

Professional Papers

1959

\title{
Effects of various asymptotic restrictions on human trial-and-error learning
}

Ridgely White Chambers

The University of Montana

Follow this and additional works at: https://scholarworks.umt.edu/etd

Let us know how access to this document benefits you.

\section{Recommended Citation}

Chambers, Ridgely White, "Effects of various asymptotic restrictions on human trial-and-error learning" (1959). Graduate Student Theses, Dissertations, \& Professional Papers. 4945.

https://scholarworks.umt.edu/etd/4945

This Thesis is brought to you for free and open access by the Graduate School at ScholarWorks at University of Montana. It has been accepted for inclusion in Graduate Student Theses, Dissertations, \& Professional Papers by an authorized administrator of ScholarWorks at University of Montana. For more information, please contact

scholarworks@mso.umt.edu. 
EFFECTS OF VARIOUS ASYMPTOTIC RESTRICTIONS

ON HUMAN TRIAL-AND-ERROR IEARNING

by

RIDGELY W。 CHAMBERS

B.A. Montana State University, 1959

Presented in partial fulfiliment of the requirements for the degree of Master of Arts

MONTANA STATE UNIVERSITY

1959

Approved by:

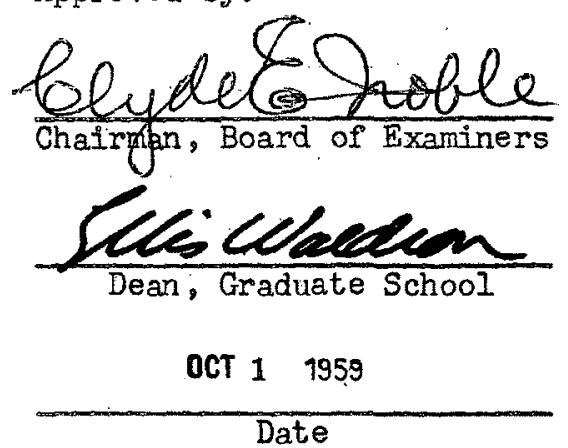




\section{UMI Number: EP40409}

All rights reserved

INFORMATION TO ALL USERS

The quality of this reproduction is dependent upon the quality of the copy submitted.

In the unlikely event that the author did not send a complete manuscript and there are missing pages, these will'be noted. Also, if material had to be removed, a note will indicate the deletion.

UMI EP40409

Published by ProQuest LLC (2014). Copyright in the Dissertation held by the Author.

Microform Edition @ ProQuest LLC.

All rights reserved. This work is protected against unauthorized copying under Title 17, United States Code

\section{Proquest}

ProQuest LLC.

789 East Eisenhower Parkway

P.O. Box 1346

Ann Arbor, MI 48106 - 1346 


\begin{abstract}
ACKNOWLEDGEMENT
The author would like to express his sincere appreciation to Doctor. Clyde Noble for understanding and guidance in preparation of this thesis, and to Professors Robert B. Ammons and Howard E. Reinhardt for helpful conments. Hyrel M. Chambers and Quentin A. Leland assisted in data analysis. The National Science Foundation. supported the research in part under Research Grant NSF-GL895.
\end{abstract}


A research program in human learning recently begun by Noble (Noble, 1954) is attempting to extend Hull's S-R reinforcement theory (Hull, 1952) from the special case of two-choice simple trial-anderror learning to the general case of multiple-choice compound trialand-error leaming. On the basis of Hull's assumptions, the following rational equation was proposed (Noble, 1957c) to describe the acquisition curves:

$$
R_{p}=a(i) r^{N}
$$

where $\mathrm{R}_{\mathrm{p}}=$ probability of correct choice based on the pooled responses of a group of $\mathrm{Ss}_{\mathrm{a}} \mathrm{a}=$ asymptote or limit of $\mathrm{R}_{\mathrm{p}} \dot{i}=$ initial probability at the outset of leaming (given by the reciprocal of the number of available, independent and mutually-exclusive responses); $r=$ rate parameter (theoretically related to stimulus conditions, task factors; work distribution, reward contingencies, and individual differences); and where $\mathbb{N}=$ number of practice trials.

Previous experiments have investigated the generality of the equation under variations of response availability (Noble, 1955, 1957a), task length (Noble, 1957b). locus of reward (C. E. Noble \& J. I. Noble, 1958). delay of reward (Noble \& Alcock, 1958), reward schedule (Taylor \& Noble, 1960), specifocity of instructions (Noble, Alcock, \& Farese. 1958), type of cholce procedure (C. E: Noble, Alcock, \& J. L: Noble, 1958), individual differences (C. E. Noble, J. I. Noble, \& Alcock, 1958), and work distribution (Noble \& Taylor. 1959). The percentage 
of variance in $R_{p}$ accounted for by Equation $I$ in these studies has ranged in 24 independent samples from $91.8 \%$ to $99.9 \%$ with the higher values predominating (mean $=98.7 \%$ ).

The present experiment is a more stringent test of the applicability of Equation 1 in which the limit of acquisition (a) was varied for different groups, all other variables being kept constant. Various asymptotic restrictions were introduced by manipulating the percentage of reinf orceable responses available to $S$ s in a stand ard 10-link problem. The empirical question, in other words, was to determine the influence of different "degrees of solubility" on the basic form of human trial-and-error aequisition curves.

Most of the earlier investigations discovered a high degree of predictability for Equation I when $\stackrel{1}{\text { was }}$ varied and a held constant. This experiment. was designed to assess the predictability of the formula under exactly the opposite conditions. Our expectation was that Equation 1 would continue to predict human behavior with approximately the same accuracy as before, and that $\underline{r}$ would be some function of $\underline{a}$. Due to the nature of the equation, it was also deduced that initial proficiency would vary directly with these asymptotic restrictions.

\section{Method}

Apparatus. The Selective Mathometer, described in detail elsewhere (Noble \& Farese, 1955), is shown in Fig. 1. It is an automatic 19-key pushbutton device, designed for the study of complex learning in human Ss. Pacing știmuli are presented serially by an electronIcally-controlled slide projector, to which $\underline{S}$ responds by selecting keys on a semicircular panel. The slides consisted of an invariant 
sequence of 10 electrical circuit symbols, and the correct solution for all Ss was to press the odd-numbered keys in the order: 3,13 , $17,9,19,5,1,11,7,15$. Scores were recorded by polygraph and counters. Time constants for stimulus duration (2-seca); intraserial interval (1.75-sec。), interserial interval (7.50-sec。), reward delay $\left(0-s_{0} c_{0}\right)$ and reward duration $\left(.75-\right.$ seco $\left._{0}\right)$ were the same as in most previous experiments. AII data were collected in an air-conditioned laboratory, shown in Fig. 2; $\mathrm{E}$ and $\mathrm{S}$ were isolated in adjoining sound treated chambers connected by a one-way vision mirror and an inter-com system.

Subjects: The total of 220 Ss sampled were students enrolled at Montana State University during the spring and summer quarters of 1959, of whom 70 were rejected due to machine failure, $E$ error, $S$ error, and for the purpose of sub-group balancing. The distribution of rejections were as follows:

\begin{tabular}{|c|c|c|c|c|c|}
\hline \multirow[b]{2}{*}{$\begin{array}{l}\text { Reason for } \\
\text { Rejection }\end{array}$} & \multicolumn{5}{|c|}{ Groups } \\
\hline & 10 & 9 & 8 & 6 & 4 \\
\hline $\begin{array}{l}\text { Machine } \\
\text { failure }\end{array}$ & 8 & 4 & 12 & 13 & 4 \\
\hline E error & 1 & $\therefore$ & 2 & 3 & 2 \\
\hline S error & 2 & 1 & & & \\
\hline $\begin{array}{l}\text { Sub-group } \\
\text { balancing } \\
=\ldots\end{array}$ & & 7 & 2 & 6 & 3 \\
\hline
\end{tabular}

The remaining $150 \mathrm{Ss}$ were composed of 74 men and 76 women, whose ages 
ranged from 17 to 59 years (mean $\approx 25.18 \mathrm{yr}$ )." None had previous experience with the Mathometer. All received standard instructions (Noble, Alcock, \& Farese, 1958, p. 255) which emphasized accuracy, quick responding, and the dependency of the green light on correct choices. The nature of the apparatus and the instructions was such that Ss received no indication of differential treatment in the various conditions.

Procedure. The Ss were divided into five experimental groups of 30 each, and assigned to the different conditions by a simple forwardreverse counterbalancing plan. 'The treatments differed in the fact that the number of reinforceable keys varied from 4 to 10 . The reference or control goup (Group 10) practiced und er standard conditions where 10 keys were available and all rewardable, thus making it possible for Ss in this group to find the appropriate key for each stimulus. Group 10 thus worked on a soluble problem, where $\mathrm{a}=1.00$. Group 9 was presented with the same stimuli and had the same keys available as Group 10, but one of the keys was non-reinforceable; i.e. one key always failed to produce reward or feedback, making it possible for Ss in this group to find an appropriate key for only 9 of the 10 stimuli. Group 9 therefore worked on an insoluble problem, where a $=.90$. For Group 8 the situation was the same as above except that two keys were non reinforceable; hence $a=80$. Group 6 had four keys nonreinforceable, giving $a=.60$. Final ly, Group 4 practiced with six non-reinforceable keys, so a $=40$.

The four groups whose asymptotic values were less than 1.00 were further sub-divided into three equal subgroups $(n=10)$ which were dif- 
ferentiated from each other by the pattern of non-reinforceable keys. In 211 cases the keys were eliminated by random selection as shown below:

\begin{tabular}{|c|c|c|c|}
\hline & & Keys Éliminated & \\
\hline Groups & Subgroup I & Subgroup 2 & Subgroup 3 \\
\hline 9 & 9 & 17 & 3 \\
\hline 8 & 9.5 & 9.15 & 1,7 \\
\hline 6 & 3.13 .17 .9 & $3,13,9,15$ & $3.9,11,15$ \\
\hline 4 & $3,19,1,11,7,15$ & $9,19,5,1,11,25$ & $3,13,9,5,11,15$ \\
\hline
\end{tabular}

A non-correction procedure (C. E. Noble, Alcock, \& J. L. Noble, 1958) was used throughout, with $\mathrm{S}$ being allowed only one choice for each slide. All Ss were instructed to use the farefinger of the preferred hand only, to return the hand to the fixation plate after each response, and not to press any buttons during the inter-stimulus interval. Each S practiced for 50 trials or mastery, whichever came first, the latter being defined as five successive trials without error, a criterion which had been established in a previous study (Noble, 1957b).

Results and Discussion

The acquisition curves are presented in Fig. 3, where the probabilities of correct (reinfor ceable) responses $\left(R_{p}\right)$ are plotted as a function of trials (N) for the five values of the asymptote parameter, a. It should be enphasized that each curve contains relative frequency measurements of only those acts which are both correct $(\underline{B+})$ and rewardw able (G), and that the denominator (number of possible responses) for 
ach trial score is 10. As predicted from theoretical considerations (Hull, 1952; Noble, 1957c), all five curves are asynmetrical and sigmoidal. Moreover, they are in excellent agreement with Equation l. The bestofitting the oretical equations, obtained by minimizing the sums of the squares of the residuals to determine the rate parameter $\underline{r}$ are as follows:

$$
\begin{array}{lll}
\text { Group 10: } & R_{p}=1.00(.10) \cdot 916^{N} & {[2]} \\
\text { Group } 9: R_{p}=.90(.10) \cdot 922^{N} & {[3]} \\
\text { Group } 8: & R_{p}=.80(.10)^{\circ}=922^{N} & {[4]} \\
\text { Group 6: } & R_{p}=.60(.10)^{\circ} 913^{N} & {[5]} \\
\text { Group 4: } R_{p}=.40(.10)^{\circ} 902^{N} & {[6]}
\end{array}
$$

The computational procedure for finding $r$ has been fully described elsewhere (Noble, 1957b)。A preliminary estimate of the inflection point of the curve $\left(\mathbb{N}_{i}\right)$ was made by dropping a perpendicular from a point on the ordinate equal to the ratio a/e (where $e=2.718$ ) to the abscissa. This approximate $\mathbb{N}_{\mathfrak{l}}$ value is then substituted in the formula,

$$
\log _{e}=\frac{-\log _{e}\left(-\log _{e} i\right)}{N_{I}}
$$

to obtain an estimate of $\underline{n}$. The exact value of $\underline{r}$ is secured when the quantity $\Sigma\left(\mathrm{R}_{p}-\widetilde{\mathrm{B}}_{p}\right)^{2}$ reaches a minimum. In all previous studies, the ordinate at which acceleration of the $R_{p}$ curve passed to zero was a constant; namely, $.368=1 / \mathrm{e}$, the reciprocal of the base of the natural system of logarithms. A salient feature of the present experiment is the demonstration that this interesting property of Equation 1 is merely the special case of a soluble problem whe re the asymptotic value is 1.00. In the general case of problems ranging in degree of solubility 
(probability of mastery a a) from zero to unity, the inflection point should occur at a/e. Empirical confirmation of this prediction can be seen in Fig. 3 .

Coefficients of determination for Equations 2 through. 6 were computed directly from the variances of the residuals and the $\underline{R}_{p}$ values, as recommended by Noble (Noble, 1957b). Predictability is over $99 \%$ In every case. As a test of our hypothesis that $\underline{r}$ would be a function

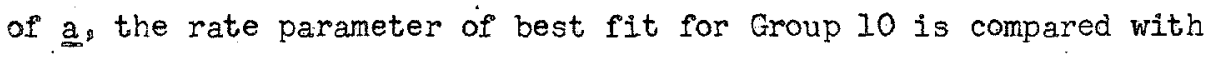
each of the others in Table 1. Judging by the relatively greater amounts of variance in $R_{p}$ scores accounted for by Equations 3, 4, 5, and 6 when their least-squares $\underset{\mathfrak{r}}{\mathrm{r}}$ values are employed rather than an $\underline{\underline{r}}$ of .916 , it is clear that the rates of change are systematically, although not monotonically, affected by manipulation of the asymptotes.

Zero accelerations occur at the following trials (Ni) for the five fitted acquisition curres: Group 10: 9.5: Group 9: 10.27\% Group $8: 10.27 \%$ Group $6: 9.1 ;$ Group $4: 7.58$. Examination of the empirical points in Fig. 3 indicates that the $\Omega_{p}$ values for Group 10 deviated markedly from its theoretical curve. A $z$ test of proportions taken at the point of maximal deviation (Trial 5) indicates that a deviation $\left(R_{p}-k_{p}\right)$ this large or larger would occur $38.98 \%$ of the time by chance. The Trial 5 discrepancy, therefore, is not significant.

As a further test of the differential-rate hypothesis, a 10x5 mixed-factorial analysis of variance was performed on the $\mathrm{R}+$ scores, arranged in 10 blocks of five trials (N) for the five experimental groups (a). The summary is shown in Table 2. Main effects of $\underline{N}$ and a and their interaction are all significant. As statistical evidence of 
non-parallel trends, the $\mathrm{Nx}$ a interaction supports our expectation that $r$ would vary as a function of 9.

It is of some int erest to evaluate the effects of degree of solubility on the difficulty (Noble, 195\%) of acquiring comparable amounts of "knowledge" (number of $\mathrm{R}+{ }^{3} \mathrm{~s}$ ) about the task or problem. To this end a trials-to-criterion analysis was made of the five groups in which the criterion was defined as that trial on which the same four correct and rewarded responses were made for the fifth triel in sucin cession. Figure 4 shows the median number of trials required to reach this criterion (Riv) as a function of the percentage of reinforceable responses (100a). The relationship is an inverse proportionality whose best-fitting, le ast-squares equation is $\mathrm{Y}=-.176 \mathrm{X}+35.924$. Calculation of the coefficient of determination indicates that $96 \%$ of the variance in $\underline{Y}$ Is attributable to $\underline{X}_{\text {e From this we conclude }}$ that difficulty is a negative linear function of increasing solubility over the present range.

Further examination of FIg。 3 indicates that the initial proficiency ( $R_{p}$ on Trial $I$ ) of the different groups varies directly with the asymptotic restrictions. By reference to Equations 2 through 6 It is evident that the theoretical origin of each group's curve $\left(\mathrm{R}_{\mathrm{p}}\right.$ on Trial 0$)$ is given by the product of $\underline{a}$ and $\underline{1}_{0}$ This important characteristic of Equation 1 may be rationalized by applying the multiplication theorem of the probability calculus, as follows. When 10 keys are available, the probability of getting an pl $_{-}$by chance alone (not considering reward contingencies) is .10 $(=1$ ). When the number of reinforceable responses is restricted, however, we are 
dealing with the combined probability of independent events, each less than urity. For this reason, we must calculate the joint probability that a particular key will be selected ( $\mathrm{R}_{+}$) and that this response will be follawed by reinforcement $(G)$. In abstract terms: $p(\underline{R}+n \underline{G})=$ $p\left(R_{+}\right) \circ p(G)$. In the case of Group 4 , for example, $p(\underline{R+})=i=.10$ and $p(G)=2=040 \%$ hence $\mathrm{B}_{p}$ on Trial $0=\mathrm{a} \cdot \mathrm{i}=04$. The joint probabilities of the other groups are computed in similar fashion. Thus is the rationale of Equation 1 directly coordinated with the relative frequency theory of probabilityo

In conelusion, it appears from these results that Equation 1 has again proved itself to be an excellent predictor of human acquisition data in omplex leaming situations. The versatility of the equation is indicated not only by with an error of less than $1 \%$, but also by the extent to which it lends itself to systematic formulation in probability terms.

Summary

This experiment investigated the effects of asymptotic restrictions on the forms of acquisition curves in a complex trial-and-error learning problem In man. One hundred fifty college students, divided into five experimental groups of $30 \mathrm{Ss}$ each. practiced a series of 10 pushbutton responses on the Selective Mathometer for 50 trials. The experimental variable consisted of manipulating the number of reinforceable keys in the various groups to produce 40\%, 60\%, 80\%, 90\%, and 100\% limits on the attainable levels of mastery.

The response probability $\left(\mathrm{B}_{\mathrm{p}}\right)$ curves were asymmetrical and sigmoidal when plotted as a function of amount of practice (N). Each group's 
curve originated at a hypothetical $\mathrm{R}_{p}$ value given by the combined probability of making a correct choice (ij) and of receiving reinforcement (a). Noble's rational equation $\mathrm{n}_{\mathrm{p}}=\mathrm{a}(\mathrm{i}) \mathrm{r}^{\mathrm{N}}$ accounted for over $99 \%$ of the variance in the dependent variable scores $\left(\mathrm{R}_{\mathrm{p}}\right)$ in all five instances. The rate parameters ( ${ }^{p}$ ) were systematically, although not monotonically, affected by variation of the asymptotes. It was shown that in general the inflection points of the theoretical curves occurred at ordinate values of $\mathrm{a} / \mathrm{e}$, where $\underline{\underline{e}}=2.718$.

An analysis of the influence of degree of solubility on difficulty agreed with the effects of asymptotic restrictions on initial proficiency. By measuring the median trials required to master four cor rect responses in all groups, it was found that difficulty was an inverse linear function of solubility. 
REFERENCES

Hall, C. Lo A behavior system. New Haven: Yale Univ. Press, 1952.

Noble, $C$. E. The difficulty-complexity relationship in complex trialand-error learning. Amer. Psychologist, 1954, 9, 443. (Abstract)

Noble, C. E. Compound trial-and-error learning as a function of response availability $\left(\mathbb{N}_{\mathbb{R}}\right)$. I. expo Psychol, $1955,49,93-96$.

Noble, C.E。 Human trial-and-error learning, Psychol. Rep., 1957 , 3. 377-398. (c)

Noble, C.E. Supplementary report: Response availability in human trial-and-error learning. Jo exp. Psychol. \& 1957, 53, 359-360. (a)

Noble, C. E. The length-difficulty relationship in compound trialand-error leaming. jo exp. Psychol, 1957, 54, 246-252. (b)

Noble, Co E。 \& Al $00 \mathrm{ck}$, Wo To Human delayed-reward learning with dif ferent lengths of task. Jo exp. Psychol., 1958, 56, 407-412.

Noble, C. E., Alcock W. T., \& Farese, F。 Jo Habit reversal under differential instructions in compound trial-and areror learning. 3. Psychol. 1958, 46, 253-264。

Noble, C. E。, Alcock, W. To, \& Noble, Jo L. The interaction of type of choice procedure with amount of practice in trial-and-error learning under two reward conditions. Jo Psychol. $1958,46,295-301$.

Noble, C. E. \& Farese, F. J. An apparatus for research in human selective learning。 Jo Psychol., 1955, 39, 475-484。

Noble, C. E。 \& Noble, Jo Lo Human trial-and-error learning under joint variation of locus of reward and type of pacing. J. exp. 
Psycho1., 1958, 56, 103-109.

Noble, C.E., Noble, J. Lo, \& Alcock, Wo T. Prediction of Individual differences in human trial-and-error learning. Percept. Mot. Skills, $1958,8,151-172$.

Noble, C. E. \& Taylor. A. Influence of work distribution upon complex learning by the non-correction and modified-cor rection methods. Jo exp. Psychol., 1959, 58, in press. Taylor, A. \& Noble, C. Ea Acquisition and extinction in human trialand-error learning under different schedules of reinforcement. J. exp. Psychol., in prep. 
APPENDIX

An informal interview was held with 50 of the Ss following the practice session on the Mathometer. The object of the int erview was

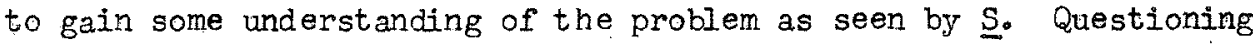
dealt with $\underline{S}^{\prime} \mathrm{s}$ approach to the solution, what $\underline{S}$ thought he was doing while trying to find the solution, and if $\underline{S}$ did not find the solution, how he accounted for his failure.

Initial "random" selection was reported by $80 \%$ of the $\underline{S}$, while $20 \%$ reported that they started with some system. Of the $80 \%$ reporting initial random selection, $40 \%$ reported that they developed a system within 10 trials. Of those starting with a system and those developing a system, $77 \%$ used the same system, that of pressing a button continuously through a trial until they received a green light, then pressing the next button until they received a green light, remembering to press the correct button for the first green light; etc. It was observed that in the majority of instances of this behavion, 9 could do this successfully until approximately 4 solutions had been found, after which considerable temporary "Ioss" af correct responses occurred. No other system was used by more than one S.

Questioning revealed that $30 \%$ were consciously aware that they were attempting to associate buttons and symbols through memorization. The balance were unable to describe how they learned to solve the problem. 
In those groups where solution was impossible, $60 \%$ felt that given sufficient time, they could have solved the problem, while $40 \%$ felt that something was wrong with the machine. Frustration and anger inspired by the task were acknowledged by $80 \%$ of the sample, the balance denying that they had had any emotional reaction. In the latter case it was suspected by $\mathrm{E}$ that this was largely a defense mechanism since in most instances ample evidence of irritation had been observed in the form of frowns, biting of lips, beating on the response panel, and excessive vigor of button pressing.

In general the most apparent behavior characteristic noted by $\underline{\mathbf{E}}$ during questioning was the unawareness of the means by which learning took place. E felt that many of the answers on which the preceding tabulation was básed were purely post hoc rationalizations by $\underline{\text {. }}$ 
Fig. 1. Floor plan of the Selective

Learning Research Laboratory 


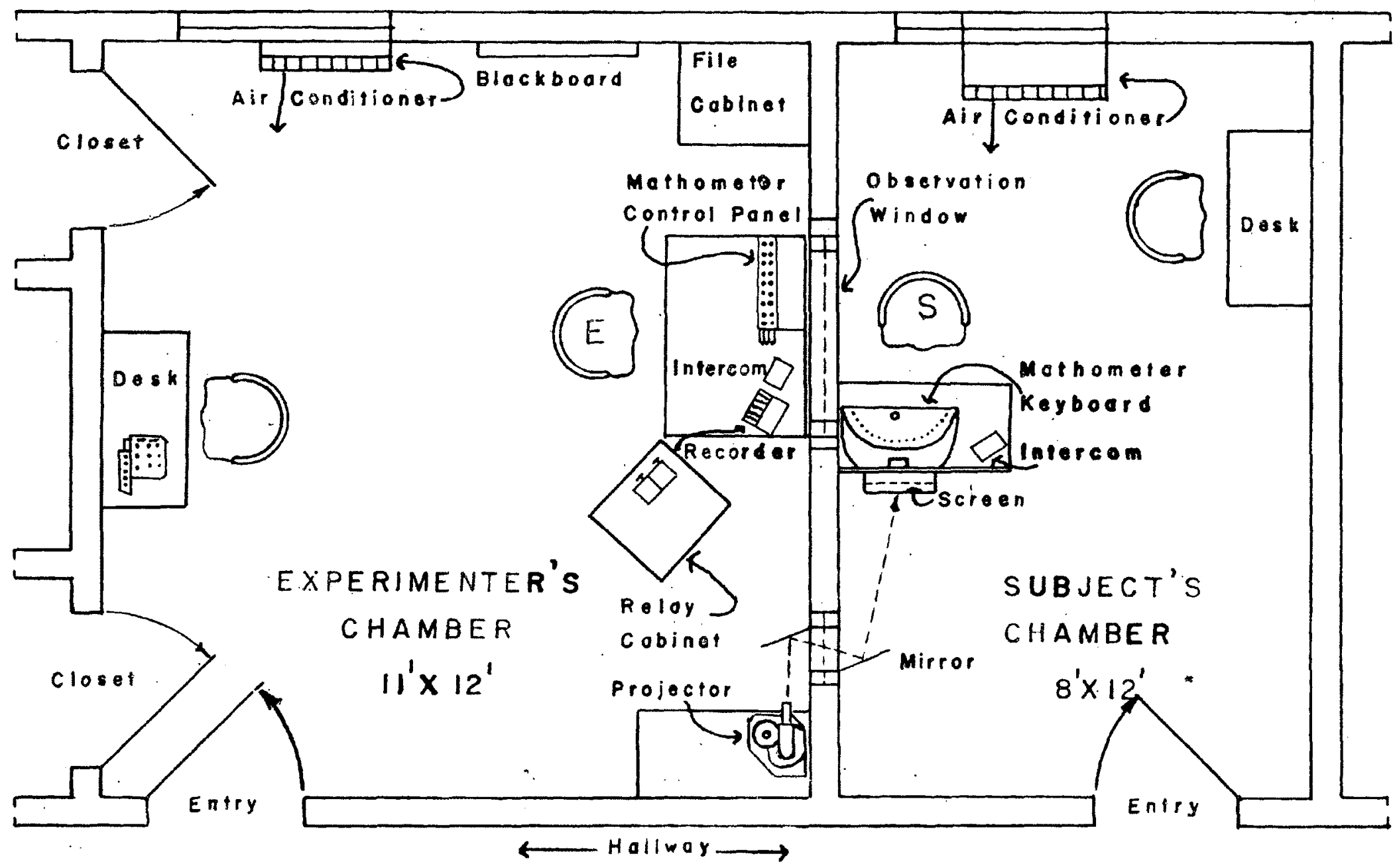


Fig. 2. The Selective Mathometer 


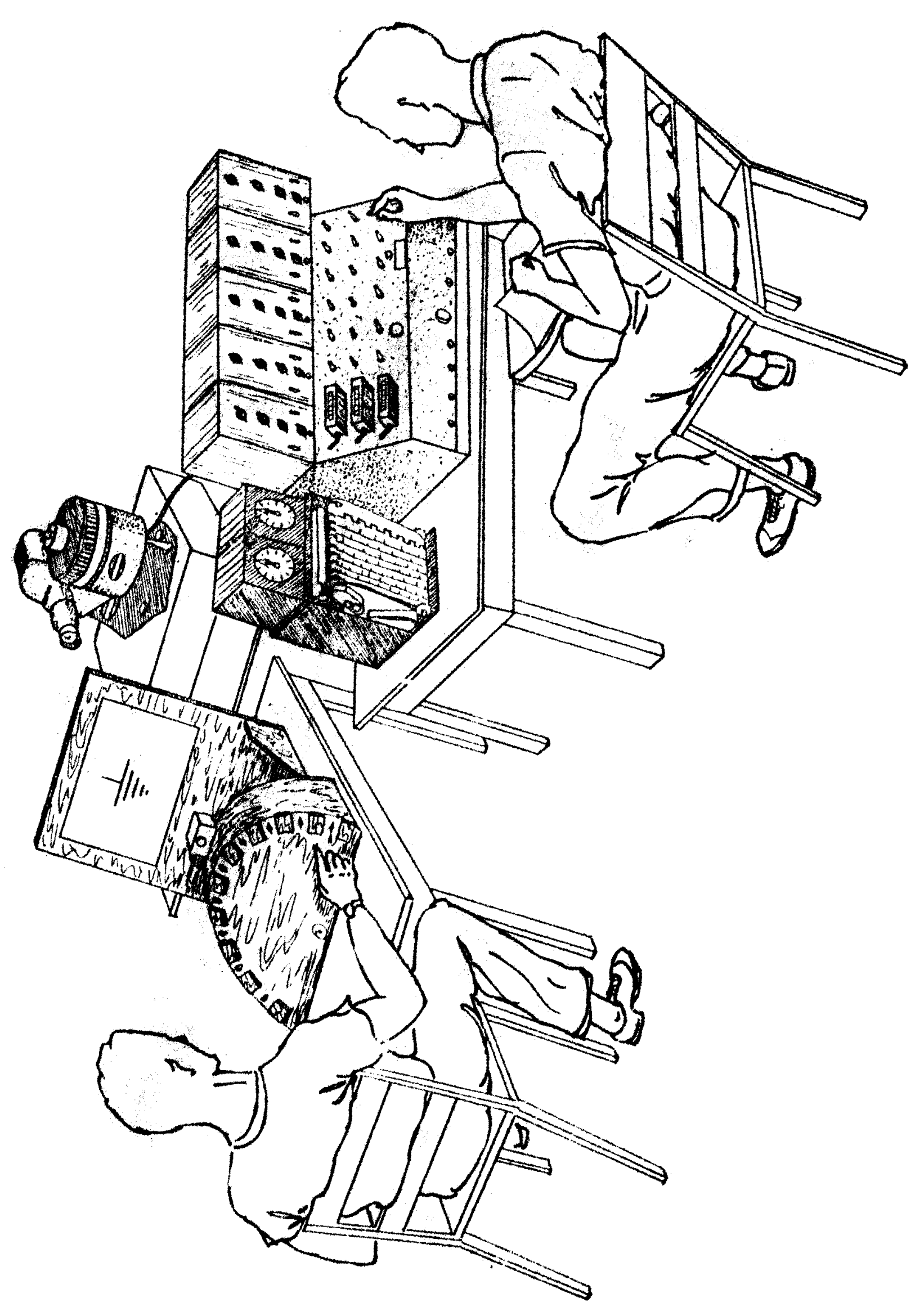


Fig. 3. Compound trial-and-error learning ( $\mathrm{R}_{\mathrm{p}}$ ) as a function of practice (N) with different asymptotes (a) as the parameter. The origins are rational. 


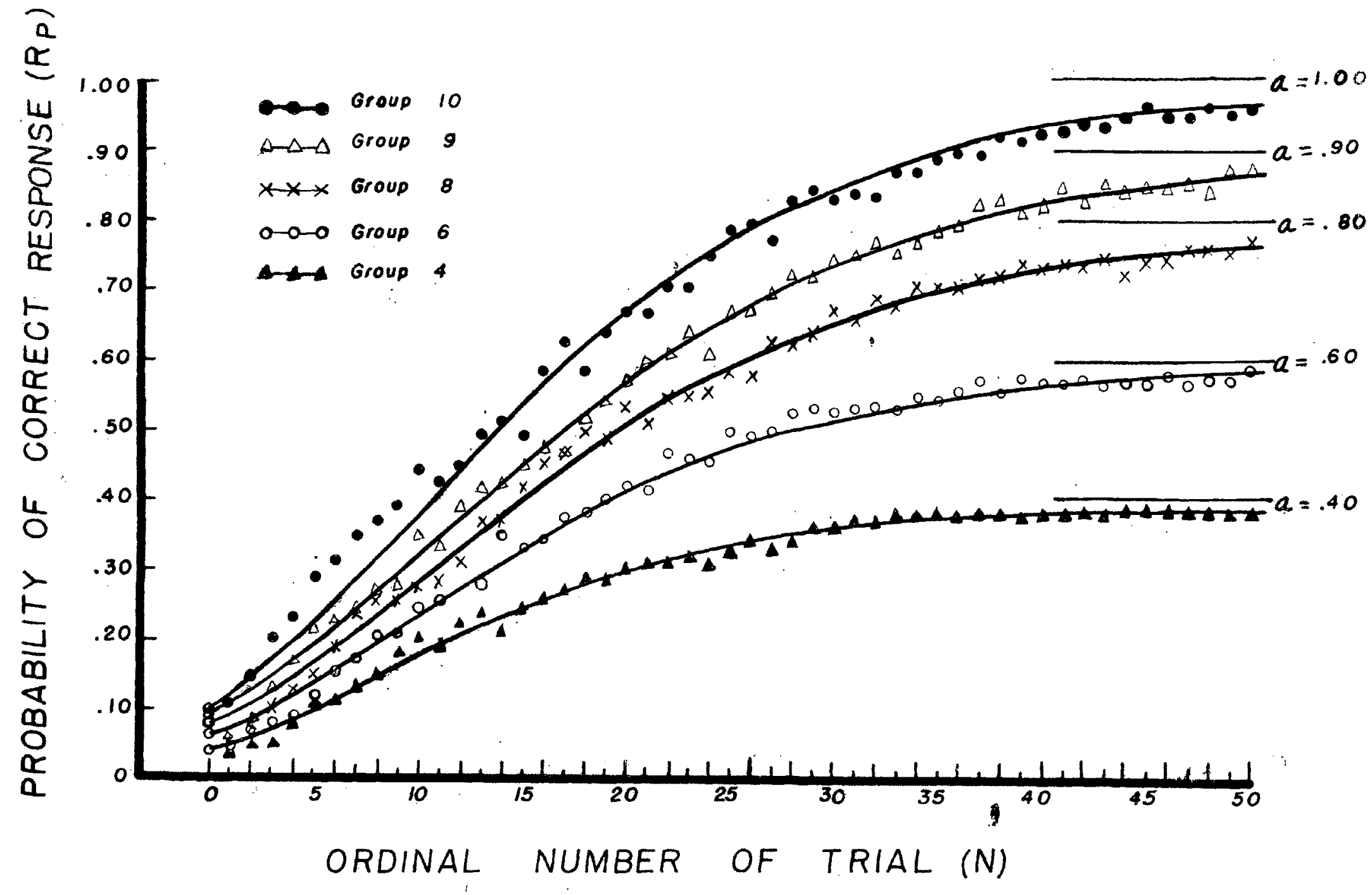


Fig. 40 Difficulty in learning four choices $\left(R_{N}\right)$ as a function of degree of solubility (100 a) of the 10-link problem. The fitted line is empirical. 


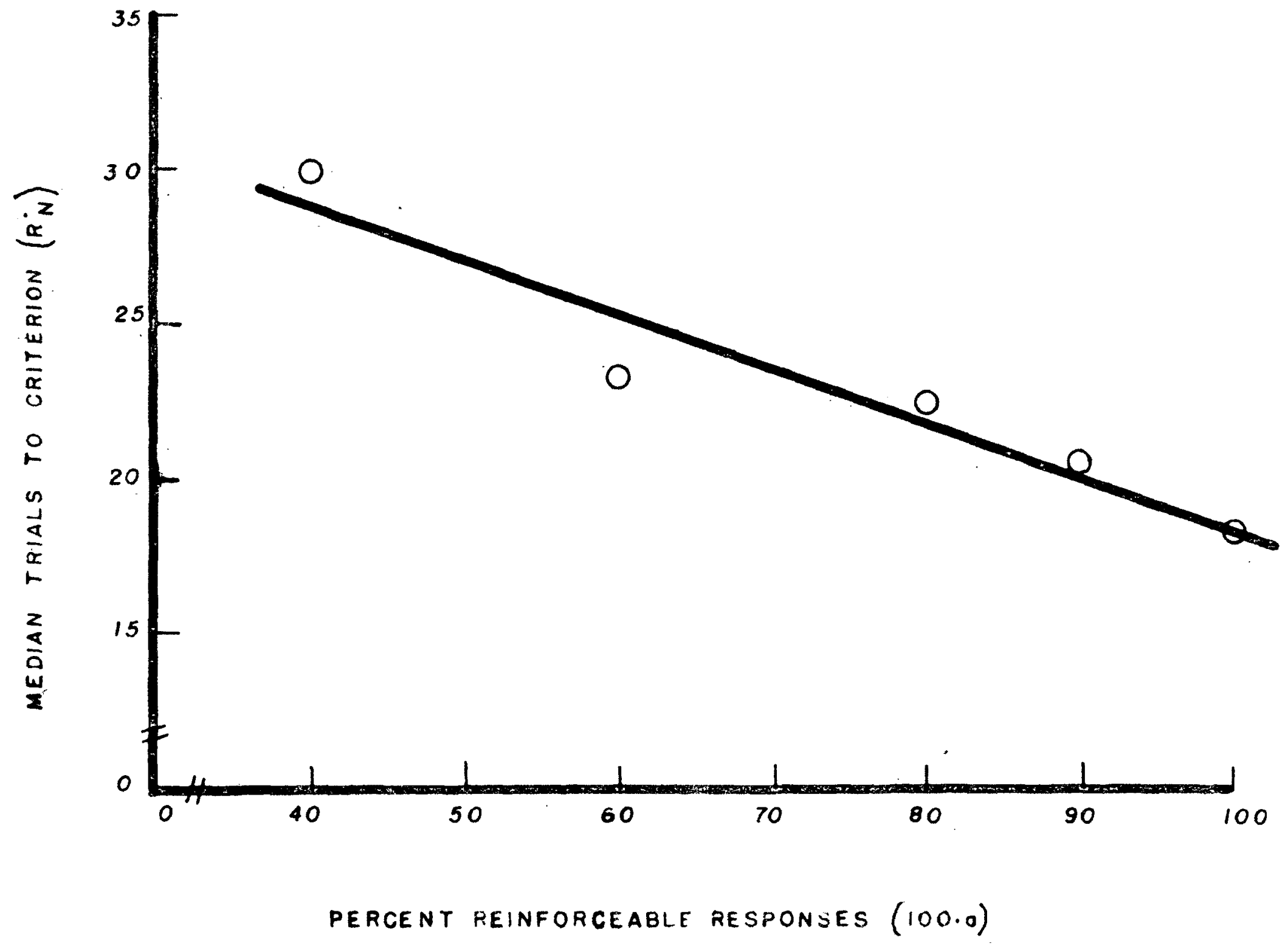


Table 1

Rate Parameter of Group 10 Compared with the Rate Parameters of Best Fit for the Other Experimental Groups

\begin{tabular}{rrrr}
\hline Group & \multicolumn{1}{r}{} & Goodness-of fit Index (\%) & $\underline{\underline{r}}=.916$ \\
\hline 10 & .916 & 99.06 & \\
9 & .922 & 99.57 & 98.59 \\
8 & .922 & 99.41 & 98.58 \\
6 & .913 & 99.31 & 98.46 \\
4 & .902 & 99.15 & 95.17 \\
\hline
\end{tabular}


Table 2

Analysis of Variance of Correct Responses (ㅍ+)

During Successive 5-Trial Blocks for the

Variaus Experimental Groups

\begin{tabular}{|c|c|c|c|c|}
\hline Source & $d f$ & . & Mean Square & $F$ \\
\hline Between Ss & 149 & & & \\
\hline Asymptote (a) & 4 & & 18008.34 & $80.36 *$ \\
\hline Error (b) & 145 & & $224 \cdot 10$ & \\
\hline Within Ss & 1350 & & & \\
\hline Trial Blocks ( & 9 & & 15466.55 & $92.90 *$ \\
\hline Interaction ( $\underline{\mathrm{N}} \times \mathbf{a})$ & 36 & & 296.34 & $1.78 x$ \\
\hline Error (w) & 1305 & & 166.48 & \\
\hline Total & 1499 & & & \\
\hline
\end{tabular}

